\title{
Histochemical Study of the Rat Uterine Glycoconjugate Alteration following Treatment with Exogenous Gonadotropic Hormones during the Implantation Period
}

\author{
Elham Aliabadi $\mathbb{D}$, ${ }^{1}$ Zohreh Makoolati $\mathbb{D},{ }^{2}$ Tahereh Talaei-Khozani $\mathbb{D}^{1},{ }^{1}$ \\ Fakhreddin Mesbah Ardekani $\left(\oplus^{1}{ }^{1}\right.$ and Arvin Aliabadi ${ }^{3}$ \\ ${ }^{1}$ Department of Anatomical Sciences, Shiraz University of Medical Sciences, Shiraz, Iran \\ ${ }^{2}$ Department of Anatomical Sciences, Fasa University of Medical Sciences, Fasa, Iran \\ ${ }^{3}$ School of Veterinary Medicine, Kazerun Branch of Islamic Azad University, Kazerun, Iran \\ Correspondence should be addressed to Zohreh Makoolati; zohreh1438@yahoo.com
}

Received 22 May 2020; Revised 4 November 2020; Accepted 16 November 2020; Published 8 December 2020

Academic Editor: Nikolai E. Lazarov

Copyright (C) 2020 Elham Aliabadi et al. This is an open access article distributed under the Creative Commons Attribution License, which permits unrestricted use, distribution, and reproduction in any medium, provided the original work is properly cited.

\begin{abstract}
One of the female causes of infertility is anovulation which is treatable with gonadotropin hormones. These hormones affect the molecular organization of the uterus such as glycoconjugates that are the first site of contact between the blastocyst and the uterus. The objective of this project was to study the alteration of glycoconjugates on the uterine apical, Golgi zone, and basement membrane of epithelial cells and the uterine gland after hyperstimulation with pregnant mare serum gonadotropin (PMSG) $(4,8,16,24$, and $40 \mathrm{IU})$, during the implantation period. Injection of PMSG (in experimental groups) and injection of distilled water (in the control group) were followed by HCG administration (10 IU), mating, isolation of positive vaginal plug rats, and killing at 5.5 days of pregnancy. Histochemistry was done on the pregnant uterine horns with the use of WGA, DBA, PNA, ConA, SBA, and UEA lectins. The intensity of the immunohistochemical staining was scored, and quantitative data were generated. $4 \mathrm{IU}$ did not show any significant differences with the control, $8 \mathrm{IU}$ had less effect on the alteration of the Golgi zone, and apical and basement membrane glycoconjugates and $40 \mathrm{IU}$ had the least effects on the alteration of uterine gland glycoconjugates. Also, $24 \mathrm{IU}$ had the most effect on the alteration of uterine glycoconjugates. Understanding of the effects of gonadotropin hormones at the uterine level in implantation time helps to optimize hormonal manipulation for improving the outcome of assisted reproductive procedures. It seems that the optimal dose for superovulation and less alteration in uterine glycoconjugates of rats at implantation time were induced by the administration of 8 IU PMSG.
\end{abstract}

\section{Introduction}

Infertility is a global health issue and affects about $10-15 \%$ of reproductive-age couples. The etiologies of infertility are male and female factors [1]. One cause of infertility is anovulation which is the most common etiology of female infertility $[2,3]$. This problem is treatable with the use of gonadotropin hormones in the process of in vitro fertilization (IVF) that result in the formation of supernumerary oocytes [4]. However, in addition to superovulation, these hormones contribute to the inhibition of blastocyst implantation through its effect on the carbohydrates in the glycocalyx of endometrial cells around the time of implantation [5,
6]. The process of implantation is a highly coordinated interaction in which the embryonic trophectoderm/trophoblast establishes contact and invades the endometrial lining of the maternal uterus [7]. Before implantation can occur, the embryo must attach to the uterine tissue and the uterus must be receptive to the embryo. Since the glycocalyx of the endometrium is the first site of contact between the blastocyst and the uterus, it is possible that carbohydrates in the glycocalyx play a role in the attachment and subsequent implantation of the embryo [5]. During early pregnancy and particularly during implantation, changes in the molecular organization of the uterine epithelial cells occur [7]. It is known that cellcell interactions are mediated by surface glycoproteins and 
the glycocalyx of the surface epithelium [8]. Certain carbohydrates such as galactosamine (GalNac), fucose (Fuc), glucosamine $(\mathrm{GlcNac})$, galactose $(\mathrm{Gal})$, and mannose (Man) in the glycocalyx of surface epithelial cells are involved in the attachment and implantation of the blastocyst [9-11]. The abnormal morphology of the surface epithelium and the disruption of the glycocalyx following factors such as stress and hyperstimulation have significant implications for the success of embryo attachment and implantation [7, 12]. These factors may warrant further investigation in attempting to explain why IVF has a low success rate [13]. The modulation of carbohydrates that result in the administration of gonadotropin hormones is evaluated with lectins that are proteins of nonimmune origin with a high degree of specificity binding ability to carbohydrates [14].

Due to the ethical restriction and experimental limitation, it is difficult to generate such information in humans [15]. Thus, the effect of pregnant mare serum gonadotropin (PMSG) on specific carbohydrates in the glycocalyx of the rat endometrium around the time of implantation was investigated.

\section{Materials and Methods}

2.1. Planning and Designing Animal Experiments. Five groups (experimental animals in the four groups and one control group) with 8 rats in each of them were used for this experiment. Female Sprague-Dawley rats with the average age of 60 days were obtained from the animal unit of Shiraz Medical University at a body weight of 200$250 \mathrm{~g}$. They were allowed free access to food and water and were maintained on a $12 \mathrm{~h}$ light: $12 \mathrm{~h}$ dark cycle [5]. The Ethics Committee of the College of Shiraz University of Medical Sciences approved the study. All efforts were made to minimize the suffering of the animals, and the pregnant rats were euthanized at day 5.5 of pregnancy under deep anesthesia by diethyl ether (Merck, Germany). All experiments were performed in accordance with relevant guidelines and regulations.

Rats of experimental groups received an intraperitoneal (i.p.) injection of $4,8,16,24$, or 40 IU PMSG (purchased from NASR Pharmaceutical Co., Iran) followed by $10 \mathrm{IU}$ human chorionic gonadotropin (HCG) (purchased from Darou Pakhsh, Iran) $48 \mathrm{~h}$ later. The female rats were then mated with proven fertile male rats. Mating was established by the presence of a vaginal plug. The day of mating was termed as day 0.5 of pregnancy. The animals were killed on day 5.5 of pregnancy (day of implantation), and both uterine horns were removed from each animal [5].

In the control group, daily vaginal smears were taken from female rats in this group. The rats were injected intraperitoneally with distilled water at diestrus or proestrus phases and then $10 \mathrm{IU}$ HCG at the estrus phase. Female rats were then mated with proven fertile male rats and killed at 5.5 days of pregnancy [12]. Both uterine horns were removed.

2.2. Establishment of Pregnancy. The uterine horns were fixed in Bouin's fluid. After normal tissue preparation, uterine horns were embedded in paraffin wax. The right uterine horns were stained with hematoxylin and eosin and viewed with a light microscope. The pregnancy symptoms (i.e., invagination of the decidual area to create a pocket for the blastocyst [16]), decidual reaction [16], and presence of immune system cells [17] were investigated (Figure 1). Only animals with typical pregnancy signs were selected for lectin histochemistry on their left uterine horns.

2.3. Lectin Histochemistry. Lectin staining was performed as previously described [12]. Briefly, left pregnant uterine horn sections were mounted on poly-L-lysine coated slides, cleared, rehydrated through graded alcohols, and washed with $0.1 \mathrm{M}$ phosphate-buffered saline (PBS). Tissue sections were treated with $1 \% \mathrm{H}_{2} \mathrm{O}_{2}$ in methanol for 20 min to block the endogenous peroxidase and rinsed in PBS. Sections were incubated with peroxidase conjugated lectins for $2 \mathrm{~h}$ at room temperature. The lectins were used at $10 \mu \mathrm{g} / \mathrm{ml}$ in PBS and included WGA (wheat germ agglutinin), PNA (peanut agglutinin), DBA (Dolichos biflorus agglutinin), ConA (concanavalin A), SBA (glycine max or soybean) and UEA (Ulex europaeus agglutinin). These lectins investigate sialic acid/N-acetylglucosamine (GlcNac), galactose/N-acetylgalactosamine (Gal/GalNac), GalNac, mannose (Man), GalNac, and fucose (Fuc), respectively [18-21]. After washing in PBS for $45 \mathrm{~min}$, incubation of sections with $\mathrm{DAB} / \mathrm{H}_{2} \mathrm{O}_{2}$ solution $(0.03 \mathrm{~g} \mathrm{DAB} / 100 \mathrm{ml}$ PBS containing $200 \mu \mathrm{l}$ of $\mathrm{H}_{2} \mathrm{O}_{2}$ ) were done for $10 \mathrm{~min}$. Sections were washed with tap water for $45 \mathrm{~min}$ and counterstained with aniline blue for $30 \mathrm{sec}$. After washing with deionized water and dehydration through graded alcohols, sections were mounted. Control sections were incubated in $\mathrm{PBS}$ at room temperature.

The intensity of the positive staining in the apical membrane, Golgi zone, and basement membrane of endometrial cells and also uterine glands was determined based on an arbitrary scale by Gong et al. from 0 to 4 (no reaction to strong) [22]. This evaluation was done two times a week blindly.

2.4. Data Analysis. Data were analyzed statistically by Kruskal-Wallis and a nonparametric test of Mann-Whitney with the SPSS program (version 12.0) package. The significance level was $p<0.05$ and $p<0.002$ for the KruskalWallis and Mann-Whitney tests, respectively.

\section{Results}

The intensity of the lectin reactions in the apical membrane, Golgi zone, and basement membrane of the endometrium and uterine glands was compared, and the following results were found:

3.1. Lectin Reactivity of Apical Membrane Glycoconjugates. The apical endometrial surface of the control group reacted with all lectins with minimum intensity for PNA and maximum for ConA.

The intensity of the reactions to WGA in 16 IU significantly decreased compared with that of the control group $(p=0.001)$. DBA-reacted sugars of 24 IU of the PMSG group showed a significant increase compared to the $40 \mathrm{IU}$ of the 


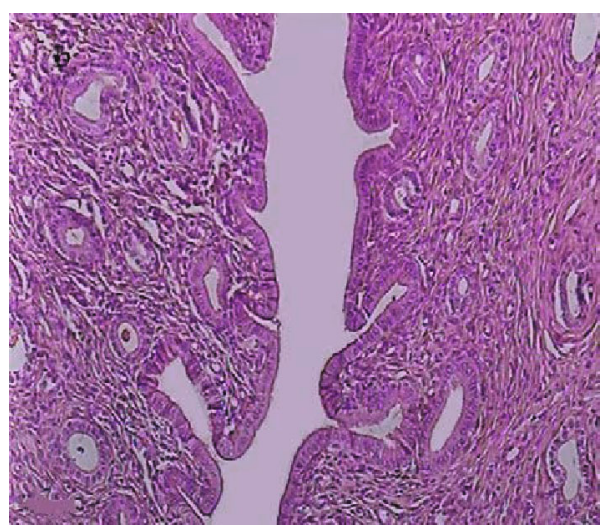

(a)

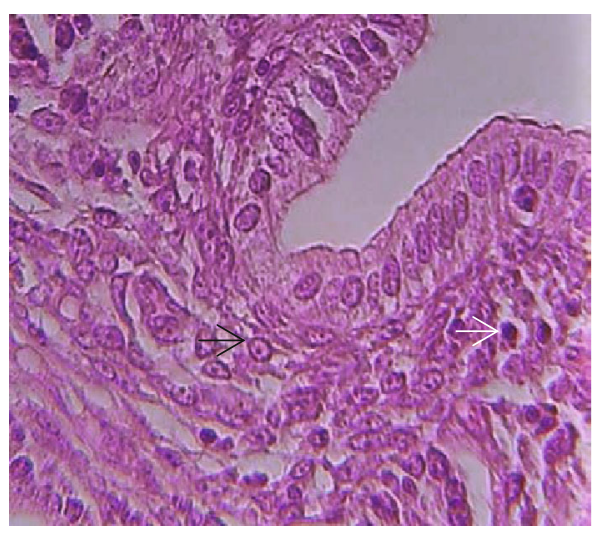

(b)

FIGURE 1: Pregnant rat uterine sections of decidual area invagination (a) and reaction (b). The white arrow indicates decidual reaction and the black arrow shows the presence of immune system cells. Magnification: (a): 20 and (b): 40.

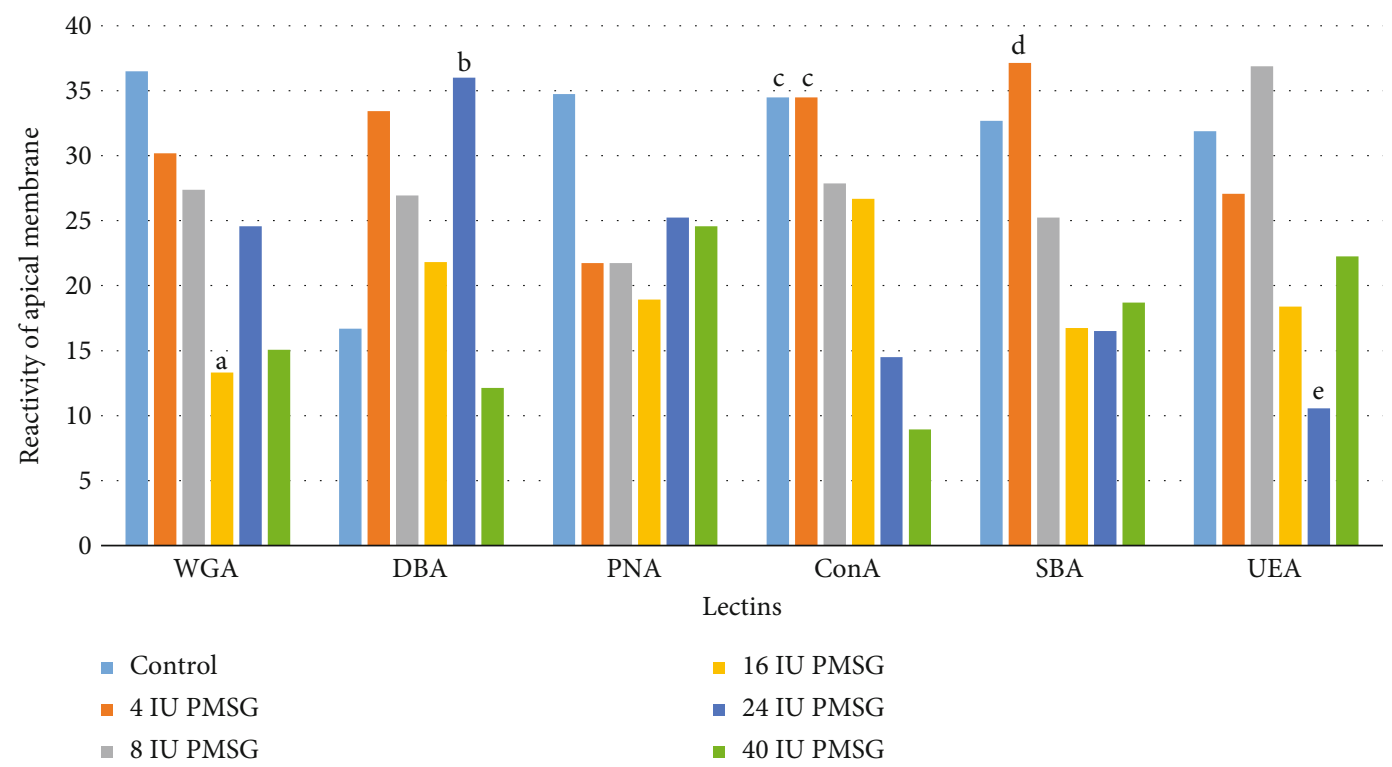

FIgURE 2: The comparison (mean rank) between the intensity of the apical membrane of endometrial cell reaction to different lectins in experimental $(4,8,16,24$, and 40 IU PMSG) and control (distilled water+HCG) groups. a Significant difference with control $(p=0.001)$. ${ }^{\mathrm{b}}$ Significant difference with $40 \mathrm{IU}$ and control $(p=0.001)$. ' Significant difference with 24 and $40 \mathrm{IU}$ ( $p=0.001$ and 0.0001 , respectively). ${ }^{\mathrm{d} S}$ Significant difference with $16 \mathrm{IU}(p=0.001)$. ${ }^{\mathrm{e}}$ Significant difference with $8 \mathrm{IU}$ and control $(p=0.0006$ and 0.0001 , respectively).

PMSG and control groups $(p=0.001)$. Reactions to ConA in 24 and 40 IU of PMSG groups significantly decreased compared with that of $4 \mathrm{IU}$ and control groups $(p=0.001$ and 0.0001 , respectively). The intensity of the reaction to SBA of $16 \mathrm{IU}$ of PMSG significantly decreased when compared with that of $4 \mathrm{IU}$ of PMSG $(p=0.001)$ and to UEA of $24 \mathrm{IU}$ of PMSG significantly decreased when compared with that of $8 \mathrm{IU}$ of PMSG and control groups $(p=0.0006$ and 0.0001, respectively; Figures 2 and 3).

3.2. Lectin Reactivity of Golgi Zone Glycoconjugates. The Golgi zone of the control group reacted with all lectins with minimum intensity for PNA and maximum for ConA. The intensity of the reactions to WGA in 16 IU significantly decreased compared with that of control group $(p=0.001)$. Significant increase was observed in the intensity of the reac- tion to DBA between $24 \mathrm{IU}$ with $16 \mathrm{IU}, 40 \mathrm{IU}$, and control groups ( $p=0.001,0.0001$, and 0.001 , respectively). Reactions to ConA in 24 and 40 IU of PMSG groups significantly decreased compared with those of $4 \mathrm{IU}$ and control groups ( $p=0.001$ and 0.0001 , respectively). Also, significant decrease was observed in the intensity of the reaction to UEA between $24 \mathrm{IU}$ with $8 \mathrm{IU}$ of PMSG concentration and control groups ( $p=0.0001$ and 0.0006, respectively; Figures 4 and 3).

\subsection{Lectin Reactivity of Basement Membrane} Glycoconjugates. The basement membrane of the control group showed no reaction in the uptake of the PNA lectin. In contrast, maximum intensity was seen for SBA so that the intensity of the basement membrane reaction to SBA in 8,16 , and 24 IU of PMSG significantly decreased relative to that of the control group ( $p=0.1,0.1$, and 0.01 , respectively). 


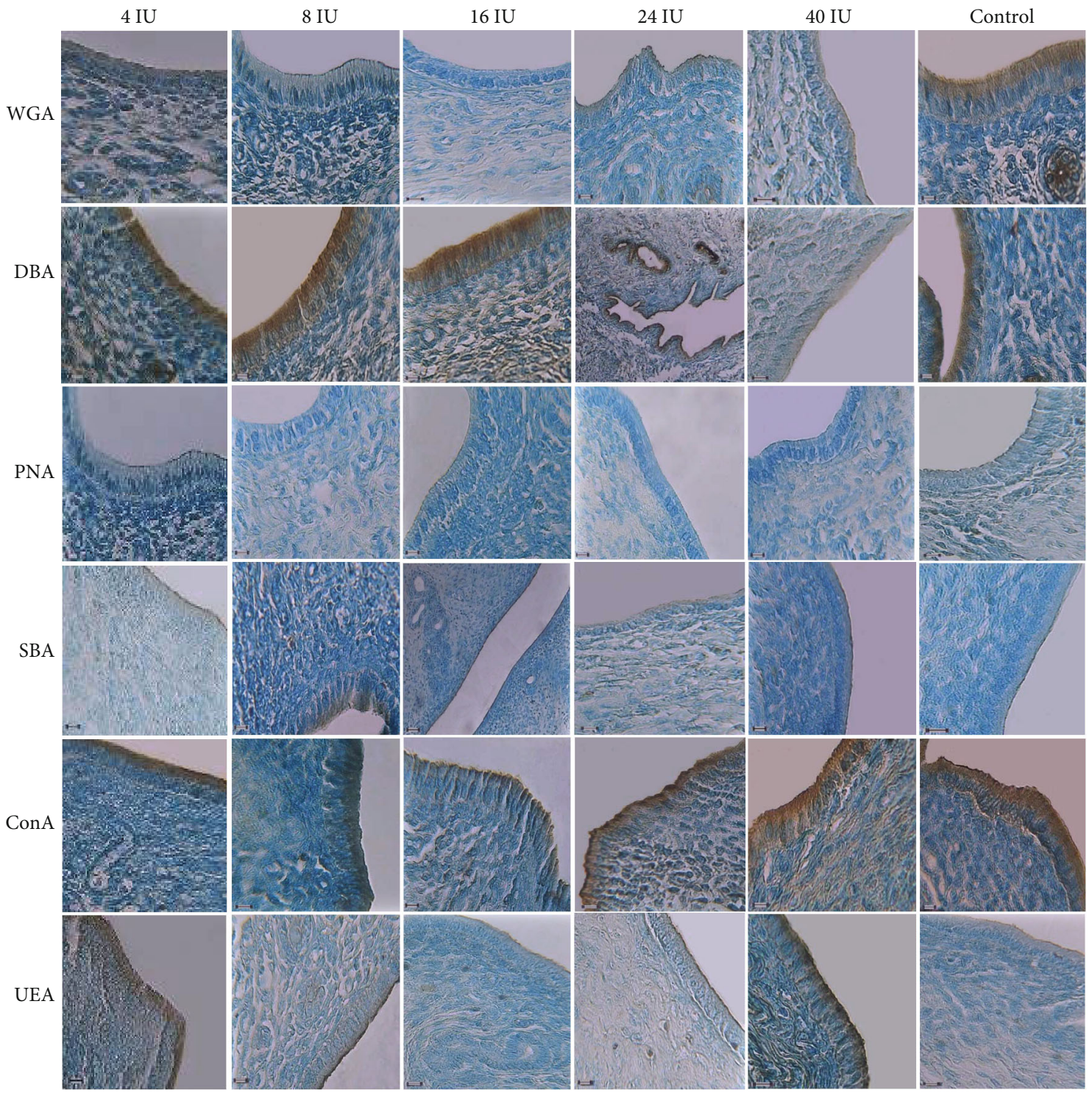

FIGURE 3: Intensity of the reaction of rat endometrium in apical membrane, Golgi zone, and basement membrane to different lectins in experimental $(4,8,16,24$, and $40 \mathrm{IU}$ PMSG) and control (distilled water+HCG) groups. Significant differences in the intensity of the reaction to different lectins were as follows: to WGA between $16 \mathrm{IU}$ and control $(p=0.001)$ in the apical membrane and Golgi zone, to DBA between $24 \mathrm{IU}$ with $40 \mathrm{IU}$ and control $(p=0.001)$ in the apical membrane, between $24 \mathrm{IU}$ with $16 \mathrm{IU}$, $40 \mathrm{IU}$ and control $(p=0.001$, 0.0001 , and 0.001, respectively) in the Golgi zone, and between 4 IU with 16 and $40 \mathrm{IU}$ in the basement membrane ( $p=0.001$ and 0.0001 , respectively), to ConA between $4 \mathrm{IU}$ and control with 24 and $40 \mathrm{IU}$ ( $p=0.001$ and 0.0001 , respectively) in the apical membrane and the Golgi zone, to SBA between $4 \mathrm{IU}$ and $16 \mathrm{IU}(p=0.001)$ in the apical membrane and between control with 8,16 , and $24 \mathrm{IU}(p=0.1,0.1$, and 0.01 , respectively) in the basement membrane and to UEA between $24 \mathrm{IU}$ with $8 \mathrm{IU}$ and control in the apical membrane ( $p=0.0006$ and 0.0001 , respectively) and Golgi zone ( $p=0.0001$ and 0.0006 , respectively).

Reaction to DBA in 16 and 40 IU of PMSG groups significantly decreased compared with that in the 4 IU concentration ( $p=0.001$ and 0.0001 , respectively; Figures 5 and 3$)$.

3.4. Lectin Reactivity of Uterine Gland Glycoconjugates. The results obtained from the control group of the uterine gland indicated that the uterine epithelium could uptake PNA with the lowest and DBA with the highest intensities. Glycocalyx of uterine glands reacted significantly with DBA in $24 \mathrm{IU}$ in comparison with $40 \mathrm{IU}$ of PMSG and control groups ( $p=0.0006$ and 0.001 , respectively). Also, in the uterine glands, significant decrease was observed in the intensity of the reaction to ConA of $40 \mathrm{IU}$ compared to 4 and $8 \mathrm{IU}$ of PMSG ( $p=0.003$ and $p=0.0001$, respectively; Figures 6 and 7).

\section{Discussions}

This study was performed to examine the effects of hyperstimulation on the glycoconjugates of the rat endometrium. Data from the present study showed that PMSG in the $24 \mathrm{IU}$ concentration had the most effects on the alteration 


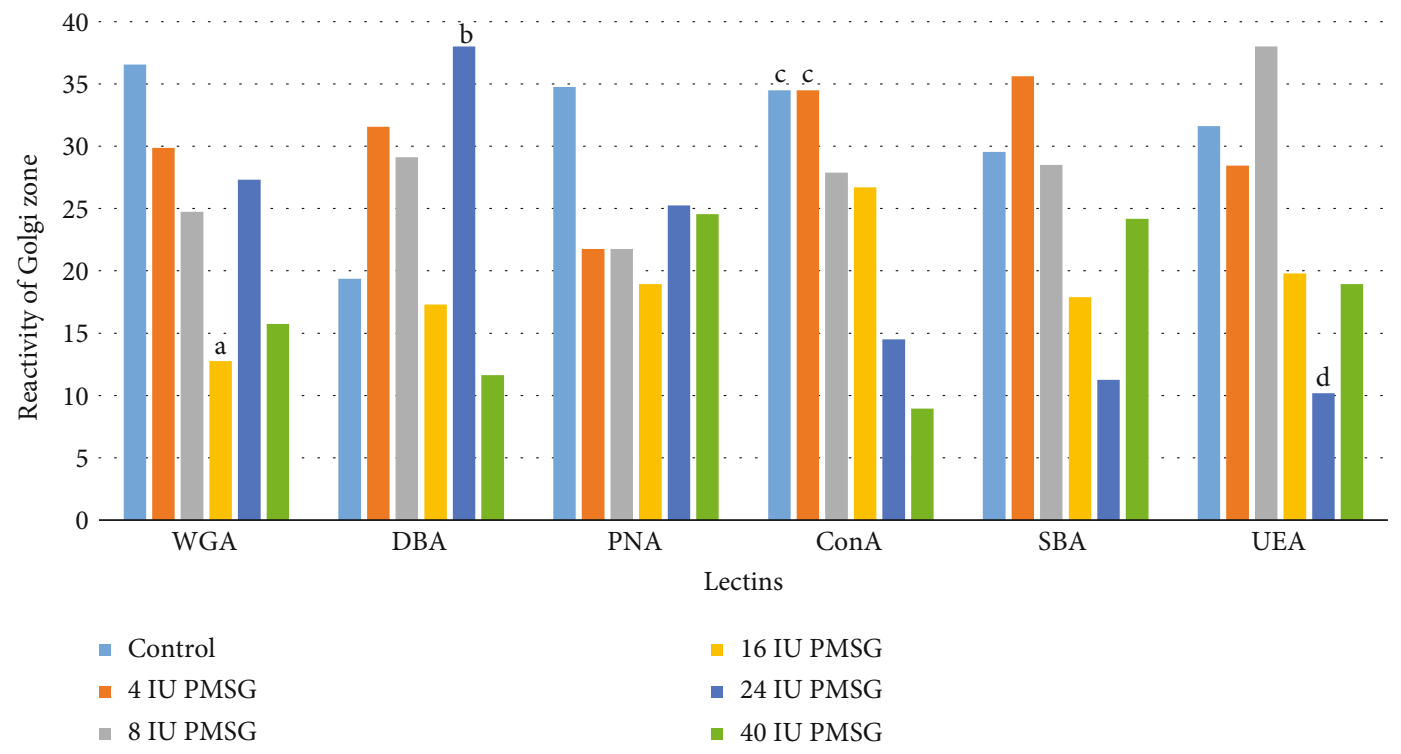

FIGURE 4: Intensity of the Golgi zone of endometrial cell reaction (mean rank) to different lectins in experimental (4, 8, 16, 24, and 40 IU PMSG) and control (distilled water+HCG) groups. a Significant difference with control $(p=0.001)$. ' Significant difference with $16 \mathrm{IU}$, $40 \mathrm{IU}$, and control $\left(p=0.001,0.0001\right.$, and 0.001 , respectively). ${ }^{c}$ Significant difference with 24 and $40 \mathrm{IU}$ ( $p=0.001$ and 0.0001 , respectively). ${ }^{\mathrm{d}}$ Significant difference with control and $8 \mathrm{IU}$ ( $p=0.0006$ and 0.0001 , respectively).

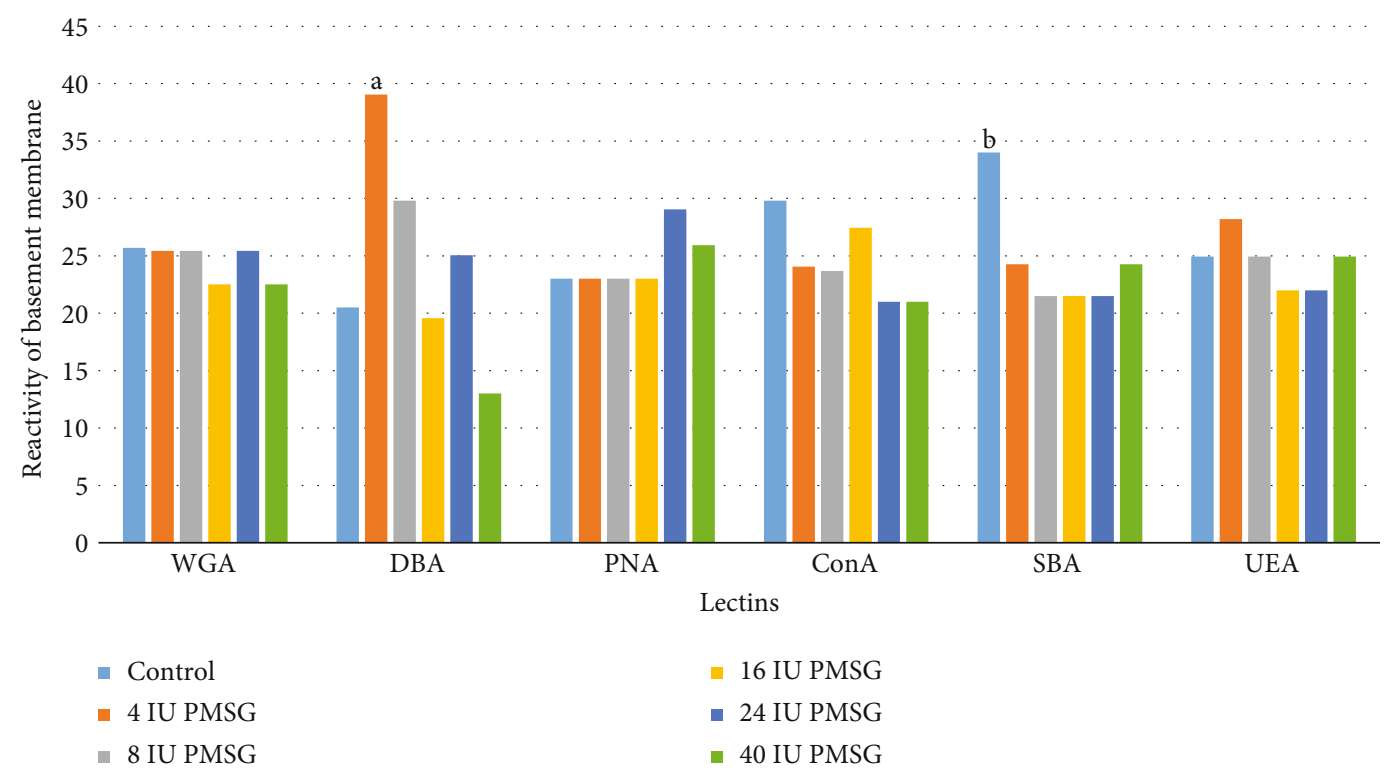

FIgURE 5: The intensity (mean rank) of the basement membrane of endometrial cell reaction to different lectins in experimental (4, 8, 16, 24, and 40 IU PMSG) and control (distilled water+HCG) groups. ${ }^{a}$ Significant difference with 16 and 40 IU ( $p=0.001$ and 0.0001 , respectively). ${ }^{\mathrm{b}}$ Significant difference with 8,16 , and $24 \mathrm{IU}(p=0.1,0.1$, and 0.01 , respectively).

of glycocalyx on the apical epithelial cell membrane, Golgi zone, and basement membrane of endometrial cells and uterine glands. In comparison with the control group, 4 IU did not show any significant differences, and the less effect on the alteration of glycoconjugates in the apical membrane, Golgi zone, and basement membrane of endometrial cells belongs to the $8 \mathrm{IU}$ PMSG. Also, less alteration of uterine gland reactivity to WGA, DBA, and UEA was observed with 8 IU PMSG and to PNA, ConA, and SBA with the $40 \mathrm{IU}$ PMSG concentration. Understanding the effects of gonado- tropin hormones at the uterine level in implantation time enables manipulation of uterine receptivity to control fertility and to improve the outcome of assisted reproductive procedures [23]. Superovulatory doses of gonadotropins result in reduced fertility in the laboratory [24]. These hormones affect the glycocalyx of the endometrium. Disruption of the glycocalyx following hyperstimulation has significant implications for the success of embryo attachment and implantation [25]. Our results showed that $4 \mathrm{IU}$ did not show any significant differences with the control; it can be suggested 


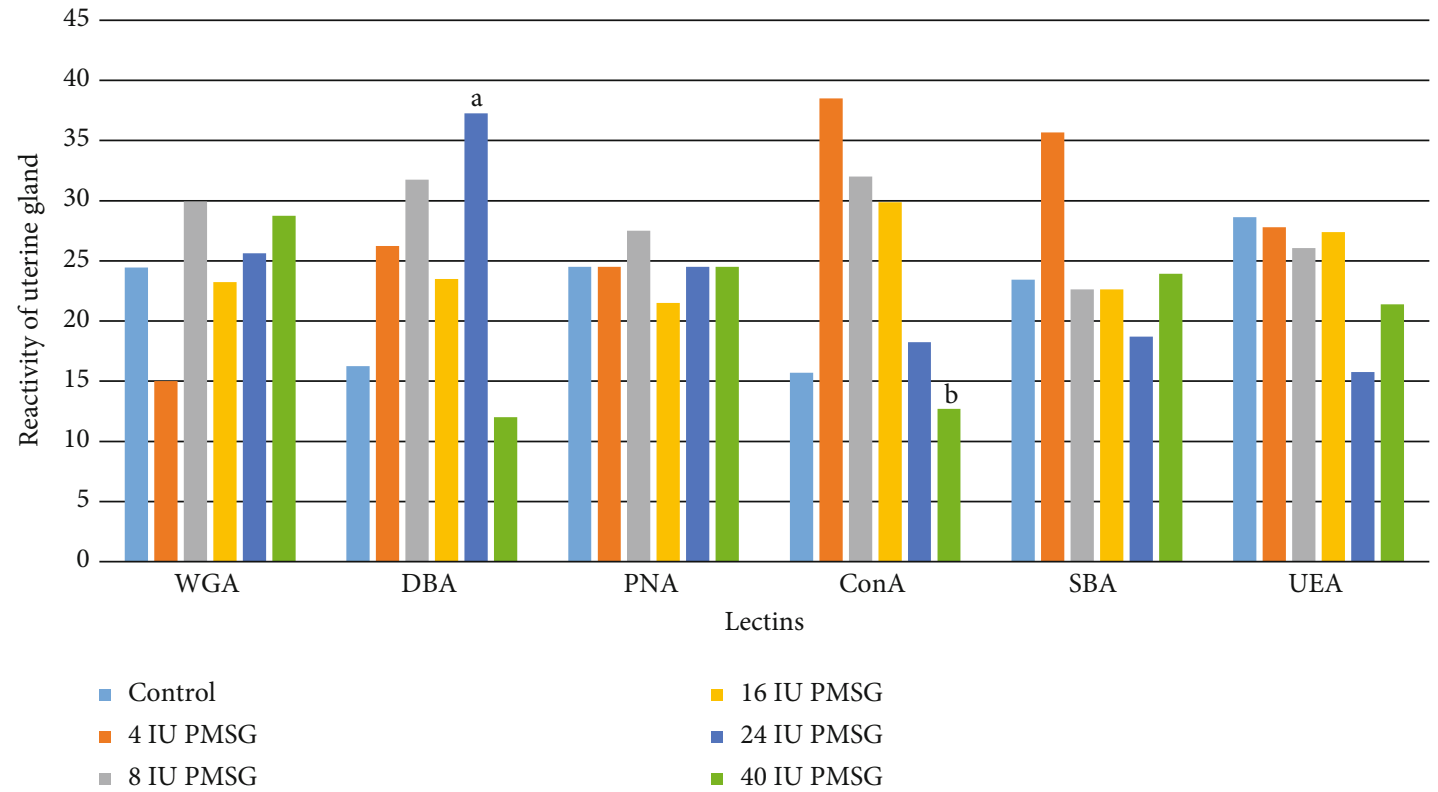

FIgURE 6: The comparison (mean rank) of the uterine gland reaction to different lectins in experimental (4, 8, 16, 24, and 40 IU PMSG) and control (distilled water+HCG) groups. a Significant difference with $40 \mathrm{IU}$ PMSG and control groups $(p=0.0006$ and 0.001 , respectively). bignificant difference with 4 and 8 IU of PMSG ( $p=0.0003$ and 0.0001 , respectively).

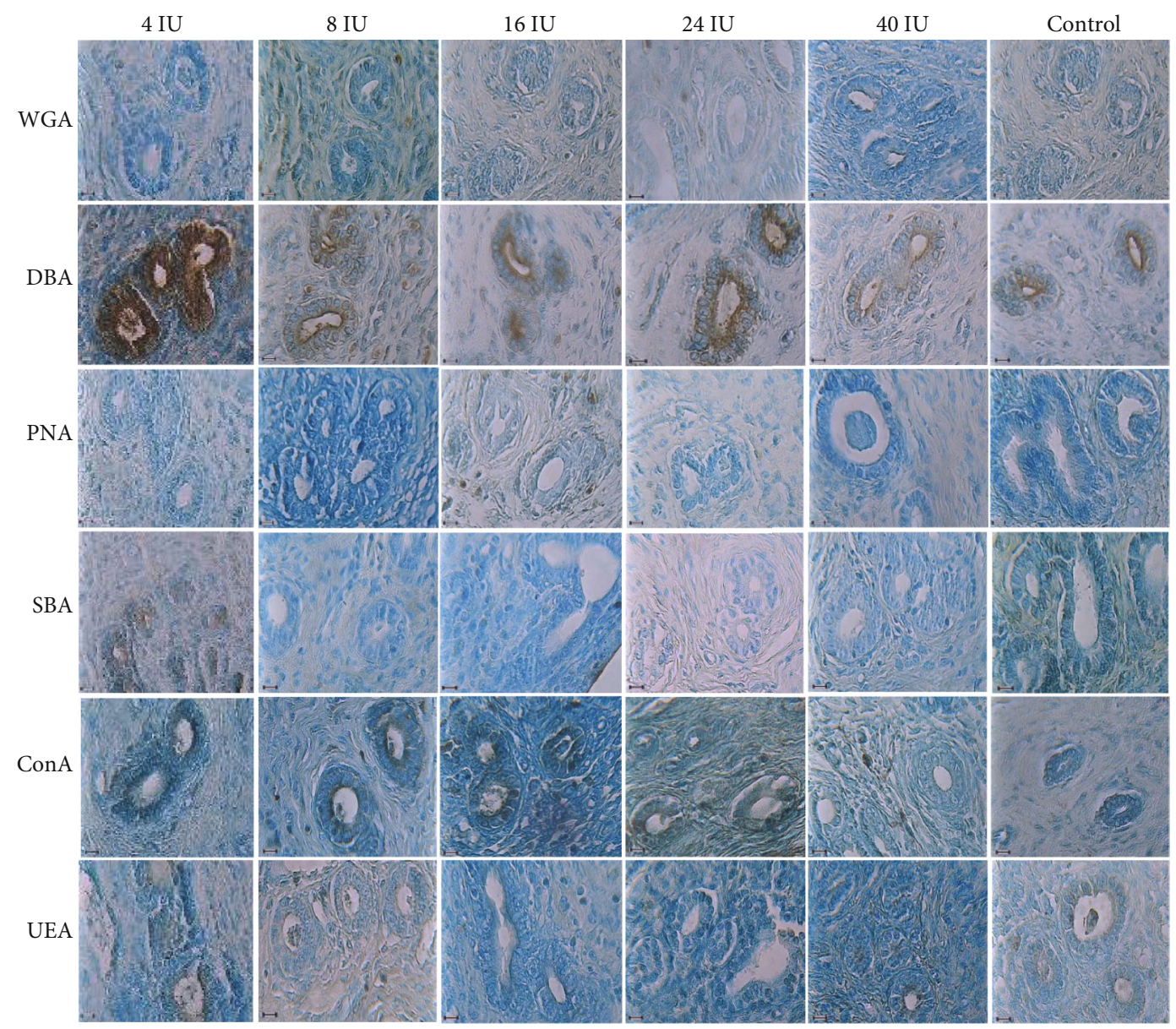

FIGURE 7: Intensity of rat uterine gland reaction to different lectins in experimental $(4,8,16,24$, and 40 IU PMSG) and control (distilled water $+\mathrm{HCG})$ groups. Significant difference in DBA-reacted sugars of $24 \mathrm{IU}$ with $40 \mathrm{IU}$ and control groups $(p=0.0006$ and 0.001 , respectively) and in ConA-reacted sugars of 40 with 4 and 8 IU of PMSG ( $p=0.0003$ and 0.0001 , respectively) was observed. 
that this dose of hormone can be used as a control group in the next studies of all studied glycoconjugates.

In this study, the epithelium of the control group reacted with WGA during the implantation period, while the reactions of the apical epithelial cell membrane and the Golgi zone to WGA in treated groups decreased. This finding is in agreement with the previous studies which showed that WGA-reacted residues increase on the rat endometrial surface during implantation [9]. During embryonic development, GlcNac mediate cell-cell and cell-matrix interaction [26]. So, it may show the recognition site for embryo implantation [27]. We observed that most effects of hyperstimulation are on the glycoconjugates of the apical membrane and Golgi zone of endometrial cells. Reduction in the glycocalyx of the hyperstimulated animals including galactosamine, fucose, and glucosamine monosaccharides and trisaccharides at the time of implantation was reported in previous studies $[5,28]$, while in 1991, Murphy and Turner demonstrated that the same carbohydrates of the uterine epithelial cell glycocalyx increase in normal pregnant rats at implantation day [9].

These carbohydrates play a role in endometrial development that is necessary for nidation [29], initiation of blastocyst adhesion to the endometrium [30], and cell-cell or cellmatrix interaction during embryonic development [26]. Alterations in the distribution of these glycoconjugates followed by hyperstimulation cause uterine functional abnormalities. As such, no implanting embryos have been reported in animals treated with this method [28]. Therefore, we should use from those concentrations of gonadotropin hormones that have the less effects on the alteration of uterine glycoconjugates at the time of implantation to improve the success rate of IVF.

Another possible explanation for implantation failure following hyperstimulation might be due to the pathological morphologic changes in the endometrium, e.g., early increase in the epithelium height of the surface and gland, increase in the number and length of microvilli, and decrease in the mitotic activity of surface epithelium and stromal cells, which adversely affect embryo attachment and implantation [28, 31]. Adverse effects of exogenous gonadotrophins on the rat and mouse endometrium at the implantation window in a dose-dependent manner was also reported by previous studies [32-34].

The basement membrane of the control group showed maximum intensity in the uptake of the SBA lectin. Implantation consists of three stages: apposition, adhesion (attachment), and invasion $[35,36]$. It is possible that carbohydrates in the glycocalyx of the basement membrane play a role in the subsequent implantation of the embryo [5]. Thus, it is rational to propose that the PMSG can reduce the receptivity of the endometrium via reduction of GalNac during the implantation period. The basement membrane of the control group also reacted with other lectins except PNA. UEA- and WGA-reacted carbohydrates were involved in cell invasion and cell-cell interaction, respectively [26, 37].

Findings of uterine glands showed positive reaction to all lectins used with the most reactivity to DBA and the least reactivity with PNA. Reaction of rat uterine glands with WGA, DBA, ConA, and UEA at days 10, 12, and 15 of preg- nancy was reported previously [38]. The data showed that these glycocalyx remains exist from the implantation start time, while it seems that PNA-reacted sugars express after implantation as Lee and Damjanov showed that PNA reacted only with some human uterine glands in the proliferative endometrium while it bound intensely to all glands in the endometrium of pregnancy [39]. Thus, it seems that the PNA expression pattern in rat uterine glands is similar as that in humans. Since uterine glands through their secretions can support the growth and development of the embryo at the peri-implantation period [39], any alteration in the glycocalyx expression can affect the blastocyst implantation indirectly.

At the time of implantation, most rat uterine gland reactivity was seen with WGA, DBA, and UEA, and 8 IU PMSG has the least effects on the alteration of these lectin reactivities in the uterine gland, and all the glycoconjugates were studied in this investigation at the apical membrane, Golgi zone, and basement membrane of endometrial cells. Thus, it seems that $8 \mathrm{IU}$ PMSG is the best concentration among the different doses of PMSG that were studied in this research. Based on the study by Fischer and Fisher [40], the best superovulatory doses of PMSG on the rate and time of ovulation and ovarian histology in gerbils was observed with 10 IU PMSG. Based on the above consideration, we concluded that the optimal dose for superovulation and less alteration in uterine glycoconjugates of rats at implantation time was induced by the administration of 8-10 IU PMSG.

\section{Abbreviations}

WGA: Wheat germ agglutinin

DBA: Dolichos biflorus agglutinin

PNA: Peanut agglutinin

ConA: Concanavalin A

SBA: Soybean agglutinin

UEA: Ulex europaeus agglutinin

PMSG: Pregnant mare serum gonadotropin

HCG: Human chorionic gonadotropin

GalNac: Galactosamine

Fuc: $\quad$ Fucose

GlcNac: Glucosamine

Gal: Galactose

Man: Mannose

IU: International unit

IVF: In vitro fertilization

i.p.: Intraperitoneal.

\section{Data Availability}

The data used to support the findings of this study are available from the corresponding author upon request.

\section{Disclosure}

This manuscript was derived from the corresponding author's study at University of Shiraz, Iran. 


\section{Conflicts of Interest}

The author declares that there are no conflicts of interest.

\section{Acknowledgments}

The authors wish to thank the Vice-Chancellor of Research, Shiraz University of Medical Sciences for offering the grant (no. 83-2265) for this work.

\section{References}

[1] Z. Heidary, M. Zaki-Dizaji, K. Saliminejad, and H. R. Khorram Khorshid, "MicroRNA profiling in spermatozoa of men with unexplained asthenozoospermia," Andrologia, vol. 51, no. 6, article e13284, 2019.

[2] S. Thatcher, "Anovulatory infertility. Causes and cures," The Journal of Reproductive Medicine, vol. 34, no. 1, pp. 17-24, 1989.

[3] V. Machado, J. Lopes, M. Patrão, J. Botelho, L. Proença, and J. J. Mendes, "Validity of the association between periodontitis and female infertility conditions: a concise review," Reproduction, vol. 160, no. 3, pp. R41-R54, 2020.

[4] J. Qin, X. Sheng, D. Wu et al., "Adverse obstetric outcomes associated with in vitro fertilization in singleton pregnancies," Reproductive Sciences, vol. 24, no. 4, pp. 595-608, 2017.

[5] S. Peverini and B. Kramer, "Superovulation affects glucosamine trisaccharides in the glycocalyx of the rat endometrium at the time of implantation," Journal of Anatomy, vol. 187, Part 2, pp. 487-490, 1995.

[6] H. Cakmak and H. S. Taylor, "Implantation failure: molecular mechanisms and clinical treatment," Human Reproduction Update, vol. 17, no. 2, pp. 242-253, 2011.

[7] F. W. Bazer, T. E. Spencer, G. A. Johnson, R. C. Burghardt, and $\mathrm{G}$. Wu, "Comparative aspects of implantation," Reproduction, vol. 138, no. 2, pp. 195-209, 2009.

[8] R. C. Burghardt, J. R. Burghardt, J. D. Taylor et al., "Enhanced focal adhesion assembly reflects increased mechanosensation and mechanotransduction at maternal-conceptus interface and uterine wall during ovine pregnancy," Reproduction, vol. 137, no. 3, pp. 567-582, 2009.

[9] C. Murphy and V. Turner, "Glycocalyx carbohydrates of uterine epithelial cells increase during early pregnancy in the rat," Journal of Anatomy, vol. 177, pp. 109-115, 1991.

[10] A. L. Niklaus, C. R. Murphy, and A. Lopata, "Ultrastructural studies of glycan changes in the apical surface of the uterine epithelium during pre-ovulatory and pre-implantation stages in the marmoset monkey," The Anatomical Record: An Official Publication of the American Association of Anatomists, vol. 255, no. 3, pp. 241-251, 1999.

[11] D. J. Chávez and T. L. Anderson, "The glycocalyx of the mouse uterine luminal epithelium during estrus, early pregnancy, the peri-implantation period, and delayed implantation. I. Acquisition of Ricinus communis binding sites during pregnancy 1," Biology of Reproduction, vol. 32, no. 5, pp. 1135-1142, 1985.

[12] E. Aliabadi, Z. Makoolati, T. Talaei-Khozani, and F. Mesbah Ardekani, "Stress affects surface glycoconjugates of the rat endometrium at the time of implantation," Glycoconjugate Journal, vol. 34, no. 5, pp. 671-677, 2017.

[13] M. Massimiani, V. Lacconi, F. la Civita, C. Ticconi, R. Rago, and L. Campagnolo, "Molecular signaling regulating endome- trium-blastocyst crosstalk," International Journal of Molecular Sciences, vol. 21, no. 1, p. 23, 2020.

[14] M. J. Marcos, E. Villar, F. Gavilanes, G. G. Zhadan, and V. L. Shnyrov, "Compact residual structure in lentil lectin at $\mathrm{pH}$ 2," European Journal of Biochemistry, vol. 267, no. 7, pp. 2127-2132, 2000.

[15] L. Grimm, A. Cooper, A. Beltsos, and R. Jeelani, "Implantation: cross talk of the developing embryo and endometrium," in Innovations In Assisted Reproduction Technology, IntechOpen, 2020.

[16] K. Y. Lee and F. J. DeMayo, “Animal models of implantation," Reproduction, vol. 128, no. 6, pp. 679-695, 2004.

[17] P. Viganò, S. Mangioni, F. Pompei, and I. Chiodo, "Maternalconceptus cross talk-a review," Placenta, vol. 24, pp. S56-S61, 2003.

[18] R. Lotan, E. Skutelsky, D. Danon, and N. Sharon, "The purification, composition, and specificity of the anti-T lectin from peanut (Arachis hypogaea)," Journal of Biological Chemistry, vol. 250, no. 21, pp. 8518-8523, 1975.

[19] M. E. Etzler, S. Gupta, and C. Borrebaeck, "Carbohydrate binding properties of th Dolichos biflorus lectin and its subunits," Journal of Biological Chemistry, vol. 256, no. 5, pp. 2367-2370, 1981.

[20] I. J. Goldstein, H. C. Winter, and R. D. Poretz, "Plant lectins: tools for the study of complex carbohydrates," in New Comprehensive Biochemistry, pp. 403-474, Elsevier, 1997.

[21] A. Leathem and N. Atkins, Lectin binding to paraffin sections. InTechniques in Immunocytochemistry Vol. 2, G. R. Bullock and P. Petrusz, Eds., Academic Press. Google Scholar, London, 1983.

[22] H. Gong, W. Ye, T. F. Freddo, and M. Rosario Hernandez, "Hyaluronic acid in the normal and glaucomatous optic nerve," Experimental Eye Research, vol. 64, no. 4, pp. 587595, 1997.

[23] M. Hosie, V. Terry, and C. Murphy, "Expression of glucosamine trisaccharides on the rat uterine surface is altered by clomiphene citrate.-III. Relationship with implantation regimes and pregnancy," Acta Histochemica, vol. 105, no. 4, pp. 329-338, 2003.

[24] O. Gregoriou, N. F. Vlahos, S. Konidaris, K. Papadias, D. Botsis, and G. K. Creatsas, "Randomized controlled trial comparing superovulation with letrozole versus recombinant follicle-stimulating hormone combined with intrauterine insemination for couples with unexplained infertility who had failed clomiphene citrate stimulation and intrauterine insemination," Fertility and Sterility, vol. 90, no. 3, pp. 678683, 2008.

[25] J. Evans, L. A. Salamonsen, A. Winship et al., "Fertile ground: human endometrial programming and lessons in health and disease," Nature Reviews Endocrinology, vol. 12, no. 11, pp. 654-667, 2016.

[26] P. Sretarugsa, P. Sobhon, P. Bubpaniroj, and V. Yodyingyuad, "Inhibition of implantation of hamster embryos by lectins," Contraception, vol. 35, no. 5, pp. 507-515, 1987.

[27] A. Whyte and T. Robson, "Saccharides localized by fluorescent lectins on trophectoderm and endometrium prior to implantation in pigs, sheep and equids," Placenta, vol. 5, no. 6, pp. 533540, 1984.

[28] B. Kramer and G. De Wet, "Exogenous gonadotropin administration affects the glycocalyx of rat endometrial epithelial cells during the period of implantation," Journal of 
Assisted Reproduction and Genetics, vol. 11, no. 10, pp. 504509, 1994.

[29] D. A. Duncan, M. T. Mazur, and J. B. Younger, "Glycoconjugate distribution in normal human endometrium. A lectin histochemical study," International Journal of Gynecological Pathology: Official Journal of the International Society of Gynecological Pathologists, vol. 7, no. 3, pp. 236-248, 1988.

[30] S. E. Domino, L. Zhang, and J. B. Lowe, "Molecular cloning, genomic mapping, and expression of two secretor blood group alpha $(1,2)$ fucosyltransferase genes differentially regulated in mouse uterine epithelium and gastrointestinal tract," Journal of Biological Chemistry, vol. 276, no. 26, pp. 23748-23756, 2001.

[31] S. Morin, B. Ata, and E. Seli, "Endocrine causes of implantation failure," in Recurrent Implantation Failure, pp. 135-152, Springer, 2018.

[32] B. Stein, B. Kramer, G. de Wet, and L. van der Walt, "Dosedependent effects of exogenous gonadotrophins on the endometrium of the rat," South African Medical Journal, vol. 83, no. 2, pp. 122-125, 1993.

[33] A. Dursun, F. Sendag, M. C. Terek et al., "Morphometric changes in the endometrium and serum leptin levels during the implantation period of the embryo in the rat in response to exogenous ovarian stimulation," Fertility and Sterility, vol. 82, pp. 1121-1126, 2004.

[34] M. Salehnia, M. Arianmanesh, and M. Beygi, "The Impact of Ovarian Stimulation on Mouse Endometrium: A Morphometrical Study," International Journal of Reproductive Biomedicine, vol. 4, no. 1, pp. 7-11, 2006.

[35] M. A. Ochoa-Bernal and A. T. Fazleabas, "Physiologic events of embryo implantation and decidualization in human and non-human primates," International Journal of Molecular Sciences, vol. 21, no. 6, p. 1973, 2020.

[36] G. Mor, P. Aldo, and A. B. Alvero, "The unique immunological and microbial aspects of pregnancy," Nature Reviews Immunology, vol. 17, no. 8, pp. 469-482, 2017.

[37] R. A. Ambros and R. J. Kurman, "Association of Ulex europaeus agglutinin I binding with invasion in endometrial carcinoma," International Journal of Gynecological Pathology, vol. 12, no. 4, pp. 301-306, 1993.

[38] S. Peel and J. N. Bulmer, "Lectin histochemistry of pregnant rat uterine tissues," Journal of Anatomy, vol. 188, Part 1, pp. 197205, 1996.

[39] M.-C. Lee and I. Damjanov, "Pregnancy-related changes in the human endometrium revealed by lectin histochemistry," Histochemistry, vol. 82, no. 3, pp. 275-280, 1985.

[40] T. V. Fischer and D. L. Fisher, "Effect of gonadotropins on ovulation and ovarian histology in the immature Mongolian gerbil," American Journal of Anatomy, vol. 142, no. 3, pp. 391-396, 1975. 